\title{
A prognosis model for patients with hepatocellular carcinoma and portal vein tumor thrombus following hepatic resection
}

\author{
CHENG-ZUO XIAO ${ }^{1-3^{*}}$, WEI WEI ${ }^{1,2^{*}}$, ZHI-XING GUO $^{1,2^{*}}$, SHU-HONG LI $^{1,2}$, \\ YONG-FA ZHANG ${ }^{1,2}$, JIA-HONG WANG ${ }^{1,2}$, MING SHI $^{1,2}$ and RONG-PING GUO ${ }^{1,2}$ \\ ${ }^{1}$ Department of Hepatobiliary Surgery, Cancer Centre of Sun Yat-Sen University; \\ ${ }^{2}$ State Key Laboratory of Oncology in Southern China, Guangzhou, Guangdong 510060; ${ }^{3}$ Department of General Surgery, \\ Shenzhen Shajing Affiliated Hospital of Guangzhou Medical University, Shenzhen, Guangdong 518100, P.R. China
}

Received November 23, 2014; Accepted August 17, 2015

DOI: $10.3892 / \mathrm{ol} .2015 .3677$

\begin{abstract}
The present study aimed to identify the risk factors influencing the survival of patients with hepatocellular carcinoma (HCC) affected by portal vein tumor thrombus (PVTT), following hepatic resection, and to establish a prognostic model. Between March 2001 and May 2008, 234 cases of HCC with PVTT that underwent hepatic resection were randomly divided into experimental or validation groups. The association between the clinicopathological factors and disease-free survival (DFS) and overall survival (OS) was analyzed, and the significant factors involved were used to establish a prognostic model, which was then validated. Tumor rupture, number of tumors and macroscopic vascular invasion were observed to be independent risk factors of DFS and OS. In the prognostic model, the DFS and OS of low-, medium- and high-risk patients in the experimental group were observed to be significantly different, compared to those in the validation group. In conclusion, the present study established a prognostic model for patients with HCC affected by PVTT following hepatectomy, and demonstrated that the model may be used to guide the treatment of these patients and predict their prognosis.
\end{abstract}

\section{Introduction}

Hepatocellular carcinoma (HCC) is the third leading cause of cancer mortality worldwide (1), and one of the most common types of malignant tumors in China. Hepatic resection for HCC may benefit the majority of patients with well-preserved liver

Correspondence to: Professor Rong-Ping Guo, Department of Hepatobiliary Surgery, Cancer Centre of Sun Yat-Sen University, 651 Dongfeng Road East, Guangzhou, Guangdong 510060, P.R. China

E-mail: guorp@sysucc.org.cn

*Contributed equally

Key words: hepatocellular carcinoma, hepatic resection, portal vein tumor thrombus, risk factors, prognosis model function and no evidence of portal hypertension (2). Due to the biological characteristics of HCC, 20-90\% of the diagnosed cases of HCC present with vascular invasion, particularly portal vein tumor thrombus (PVTT). Vascular invasion has been previously identified as a major risk factor for recurrence and mortality following resection of HCC (3). Although patients with HCC that exhibit vascular invasion are associated with a poor prognosis, liver resection provides improved long-term results than palliative therapies or supportive care (4). Peng et al (5) reported that hepatic resection may result in excellent long-term survival in certain patients. In those studies, the authors observed that the survival rate of patients with HCC following hepatic resection was $14.1 \%$ at 3 years, while the survival rate of patients without hepatic resection was 7.3\%. Zhang et al (6) described numerous factors that may affect the prognosis of patients affected by HCC with vascular invasion, following hepatectomy. However, there are limited studies describing the impact of hepatectomy on the long-term outcome of these patients.

In the present study, a large cohort of patients with HCC and PVTT treated with surgical resection, were analyzed restrospectively. The purpose of the study was to identify the clinical and histopathological variables that correlate with recurrence and survival. A prognosis model for patients with HCC presenting with vascular invasion was suggested, based on the risk factors observed to be associated with prognosis.

\section{Materials and methods}

Ethics. The Ethics Committee of the Cancer Center of Sun Yat-Sen University (Guangzhou, Guangdong, China) approved the present study. Written informed consent was obtained from the participants prior to enrollment in the study.

Patients. Data from a cohort of patients undergoing hepatic resection for HCC between March 2001 and May 2008 was prospectively collected and analyzed. Patients were admitted in the study according to the following selection criteria: i) Patients were not administered any therapy prior to the hepatectomy; ii) patients presented with PVTT, including macroscopic and/or microscopic vascular invasion; iii) patients had been subjected to hepatic resection, followed 
by histological examination to confirm negative surgical margins; and iv) patients did not present extrahepatic metastases, severe liver dysfunction (Child-Pugh class C) or had deceased prior to surgery. Those patients who had succumbed to diseases other than HCC were excluded from the study.

Clinicopathological variables. Among the 952 patients recruited for the study, 245 presented with PVTT. From the corresponding chart reviews, the following clinicopathological information was obtained for each patient: Gender; age; ascites; cirrhosis; levels of alanine aminotransferase (ALT) and $\alpha$-fetoprotein (AFP); serum levels of total bilirubin (TB), hepatitis B surface antigen ( $\mathrm{HBsAg}$ ), hepatitis $\mathrm{C}$ virus antibody ( $\mathrm{HCvAb})$ and albumin (ALB); tumor location, number and size; resection margin, macroscopic vascular invasion; and Edmondson Steiner grade.

Survival time was measured in months. Tumor size was assessed based on the largest dimension of the tumor specimen. The histological grades (I-IV) were determined according to the highest grade observed, using the criteria of Edmondson and Steiner (7). The width of the surgical margin was measured as the smallest distance from the tumor edge to the resection line. Vascular invasion was considered to be macroscopic if invasion of the vessel was visible macroscopically and by computed tomography (CT) and magnetic resonance imaging (MRI) examination. By contrast, microvascular invasion was defined by the presence of clusters of cancer cells floating in the vascular space line formed by endothelial cells, following histopathological examination of the resected specimens by two independent pathologists.

Patient follow-up. Measurement of AFP levels in serum, enhanced CT scan of the chest and abdomen or abdominal enhanced MRI in addition to chest $\mathrm{CT} / \mathrm{X}$-ray examination were performed in the first 1-2 months post-surgery; then, every 2-3 months in the first year, and every 3-6 months thereafter. When tumor recurrence or metastasis was suspected, further examinations, including MRI, hepatic angiography and biopsies were performed. Telephone calls were also conducted when necessary. CT and MRI scanning images were interpreted at the start of the study by a group of four radiologists, who possessed $\geq 10$ years of experience in image diagnosis, in the Department of Radiology of the Cancer Center of Sun Yat-Sen University. The follow-up for each patient data were regularly updated in the database. The follow-up period was terminated on May 1, 2013 or on the date of the patient's demise. By the end of the follow-up, 11 of the 245 patients were unable to be contacted or data was incomplete. The median follow-up of the remaining 234 patients was 20 months (range, 3-99 months).

Statistical analyses. Overall survival (OS) was measured from the date of hepatectomy until expiration, or to the most recent follow-up time. Disease-free survival (DFS) was measured from the date of hepatic resection to the date of the first diagnosis of tumor recurrence or the most recent follow-up time. Survival curves were calculated using the Kaplan-Meier method, and compared using the log-rank test. Variables observed to be significant in univariate analysis $(\mathrm{P}<0.05)$ were entered into a step-down Cox proportional hazard regression analysis to identify risk factors that correlated with DFS and OS. SPSS 16.0 software (SPSS, Inc., Chicago, IL, USA) was used to perform the statistical analyses. $\mathrm{P}<0.05$ was considered to indicate a statistically significant difference.

\section{Results}

Clinicopathological characteristics. Table I summarizes the clinicopathological characteristics of the patients with HCC exhibiting PVTT. The median age was 47 years (range, $15-80$ years, mean $=46.96 \pm 12.29$ years). At the end of the study, 63 patients had survived, and 171 patients were deceased. The median survival time was 18.0 months, and the average survival time was $31.39 \pm 28.83$ months. Patients were randomly divided into the experimental or validation groups ( $n=157$ and 77 , respectively), according to a $\sim 2: 1$ proportion, and were stratified into low- and high-risk groups by using AFP levels $=400 \mathrm{ng} / \mathrm{ml}$ as cut-off values.

Univariate analysis of survival for patients in the experimental group. Macrovascular invasion includes trunk, primary and/or secondary branch vascular invasion. In the present study, macrovascular invasion of the primary or secondary branches were solely considered. Table II contains the results of the survival analysis conducted on patients affected by primary and secondary branches vascular invasion within the experimental group. According to these results, no significant differences were observed in DFS and OS analysis between the patients with vascular invasion of the primary branches, compared to those patients with vascular invasion of the secondary branches within the experimental group (Table II). Therefore, to facilitate the subsequent statistical and clinical analyses, primary and secondary branches vascular invasion were combined together into a single category termed macrovascular invasion.

Table III summarizes the results of the univariate analysis for survival rate following hepatic resection of patients with HCC affected by PVTT. For the analysis, parameters including patient age, tumor size and levels of ALT, TB and ALB, were divided into two subgroups depending on the average values, whereas resection margin was divided into three subgroups by using 0.5 and $1.0 \mathrm{~cm}$ as cut-off values.

According to the results of the univariate analysis, levels of AFP $\geq 400 \mathrm{ng} / \mathrm{ml}$, presence of multiple tumors, tumor size $\geq 9.1 \mathrm{~cm}$, tumor rupture and macrovascular invasion were identified as significant prognostic factors $(\mathrm{P}<0.05)$ associated with poor prognosis of DFS and OS.

Multivariate analysis of survival for patients in the experimental group. The parameters that were demonstrated to be significant in univariate analysis were entered in a Cox proportional hazards model for multivariate analysis, which identified the presence of multiple tumors, tumor rupture and macrovascular invasion as independent risk factors of recurrence and survival (Tables IV and V).

Establishment and validation of a prognostic model. According to the results of the multivariate analysis, the presence of multiple tumors, tumor rupture and macrovascular invasion appeared to be independent risk factors of recurrence 
Table I. Clinicopathological characteristics of the 234 patients with HCC presenting PVTT.

\begin{tabular}{|c|c|}
\hline Variables & No. of patients $(\%)$ \\
\hline \multicolumn{2}{|l|}{ Gender } \\
\hline Male & $202(86.3)$ \\
\hline Female & $32(13.7)$ \\
\hline \multicolumn{2}{|l|}{$\mathrm{HBsAg}$} \\
\hline Positive & $217(92.7)$ \\
\hline Negative & $17(7.3)$ \\
\hline \multicolumn{2}{|l|}{$\mathrm{HCVAb}$} \\
\hline Positive & $2(0.9)$ \\
\hline Negative & $232(99.1)$ \\
\hline \multicolumn{2}{|l|}{ Ascites } \\
\hline No & $188(80.3)$ \\
\hline Yes & $46(19.7)$ \\
\hline \multicolumn{2}{|l|}{ Cirrhosis } \\
\hline No & $38(16.2)$ \\
\hline Yes & $196(83.8)$ \\
\hline \multicolumn{2}{|l|}{$\operatorname{AFP}(\mathrm{ng} / \mathrm{ml})$} \\
\hline$<400$ & $93(39.7)$ \\
\hline$\geq 400$ & $141(60.3)$ \\
\hline \multicolumn{2}{|l|}{ Tumor location } \\
\hline Left lobe & $79(33.8)$ \\
\hline Right lobe & $129(55.1)$ \\
\hline Left and right lobes & $26(11.1)$ \\
\hline \multicolumn{2}{|l|}{ Tumor number } \\
\hline Single & $158(67.5)$ \\
\hline Multiple & $76(32.5)$ \\
\hline \multicolumn{2}{|l|}{ Tumor rupture } \\
\hline No & $181(77.4)$ \\
\hline Yes & $53(22.6)$ \\
\hline \multicolumn{2}{|l|}{ Vascular invasion } \\
\hline Micro & $144(61.5)$ \\
\hline Secondary branch & $43(18.4)$ \\
\hline Primary branch & $47(20.1)$ \\
\hline \multicolumn{2}{|l|}{ Edmonson grade } \\
\hline $\mathrm{I}+\mathrm{II}$ & $123(52.6)$ \\
\hline III + IV & $111(47.4)$ \\
\hline \multicolumn{2}{|l|}{ Adjuvant TACE } \\
\hline No & 187 (79.9) \\
\hline Yes & $47(20.1)$ \\
\hline Mean age \pm SD (years) & $46.9 \pm 10.32$ \\
\hline $\mathrm{TB}(\mu \mathrm{mol} / \mathrm{l})$ & $16.9 \pm 10.1$ \\
\hline ALT (U/l) & $50.47 \pm 34.48$ \\
\hline ALB (g/l) & $41.7 \pm 4.1$ \\
\hline Tumor size (cm) & $9.12 \pm 4.60$ \\
\hline Resection margin $(\mathrm{cm})$ & $1.0 \pm 0.8$ \\
\hline
\end{tabular}

HCC, hepatocellular carcinoma; PVTT, portal vein tumor thrombus; HBsAg, hepatitis B surface antigen; HCVAb, hepatitis C virus antibody; AFP, $\alpha$-fetoprotein; TACE, transarterial chemoembolization; SD, standard deviation; ALT, alanine aminotransferase; ALB, albumin.

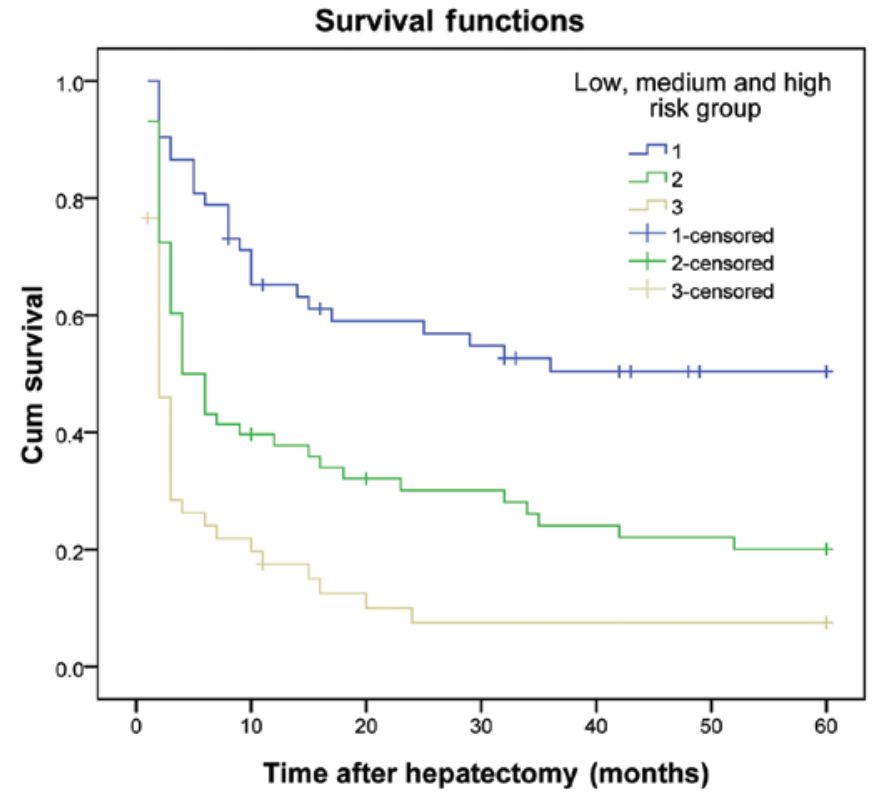

Figure 1. Disease-free survival curve for patients in the experimental group, who were divided into low-, medium- and high-risk groups. Cum, cumulative.

and survival for patients with HCC and PVTT who had been subjected to hepatic resection. Thus, group standards were established based on these three independent risk factors. Patients were divided into low-, medium- and high-risk groups (designated as group 1, 2 and 3, respectively), according to the number of risk factors that the patients presented. Thus, patients in the low-risk group presented a single tumor, no tumor rupture and no macrovascular invasion. Patients belonging to the medium-risk group exhibited one of the following characteristics: Multiple tumors, tumor rupture or macrovascular invasion, whereas patients classified as high-risk presented two or three of these characteristics.

The results demonstrated that the DFS and OS rates reduced gradually as the number of risk factors increased. The DFS and OS rates of patients in the three subgroups within the experimental group were significantly different $(\mathrm{P}<0.01)$ (Table VI and Figs. 1 and 2). The same results were obtained for the validation group $(\mathrm{P}<0.01)$ (Table VII and Figs. 3 and 4).

\section{Discussion}

Hepatic resection is an accepted first-line treatment for patients with HCC that exhibit well-preserved liver function and no evidence of portal hypertension, which is possibly curative and may result in excellent long-term survival $(8,9)$. However, patients affected by HCC that have been subjected to hepatic resection have been observed to experience a high rate of tumor recurrence, with the majority of recurrence and metastasis following resection of HCC occurring within the remaining liver (10). This is primarily due to intrahepatic dissemination of the tumor via the intrahepatic vascular system (11). Therefore, vascular invasion is considered to be an important risk factor for tumor recurrence and patient survival following resection of HCC (12). For patients with vascular invasion, the value of hepatic resection is controversial (13). 
Table II. Survival analysis of patients with vascular invasion of primary and secondary branches in the experimental group.

\begin{tabular}{|c|c|c|c|c|c|c|c|c|c|}
\hline \multirow{2}{*}{$\begin{array}{l}\text { Macrovascular } \\
\text { invasion }\end{array}$} & \multirow{2}{*}{$\begin{array}{c}\text { No. of } \\
\text { patients }\end{array}$} & \multicolumn{3}{|c|}{ DFS rate $(\%)$} & \multirow[b]{2}{*}{ P-value } & \multicolumn{3}{|c|}{ OS rate $(\%)$} & \multirow[b]{2}{*}{ P-value } \\
\hline & & 1-year & 3-years & 5-years & & 1-year & 3-years & 5-years & \\
\hline Secondary branch & 28 & 28.6 & 10.7 & 10.7 & 0.067 & 53.6 & 25.0 & 25.0 & 0.098 \\
\hline Primary branch & 38 & 15.8 & 5.3 & 5.3 & & 39.5 & 15.8 & 5.3 & \\
\hline
\end{tabular}

DFS, disease-free survival; OS, overall survival.

Table III. Survival analysis of the patients in the experimental group.

\begin{tabular}{|c|c|c|c|c|c|c|c|c|c|}
\hline \multirow[b]{2}{*}{ Variables } & \multirow{2}{*}{$\begin{array}{l}\text { No. of } \\
\text { patients }\end{array}$} & \multicolumn{3}{|c|}{ DFS rate $(\%)$} & \multirow[b]{2}{*}{ P-value } & \multicolumn{3}{|c|}{ OS rate $(\%)$} & \multirow[b]{2}{*}{ P-value } \\
\hline & & 1-year & 3-years & 5-years & & 1-year & 3-years & 5-years & \\
\hline \multicolumn{10}{|l|}{ Gender } \\
\hline Male & 136 & 35.3 & 22.8 & 18.4 & \multirow[t]{2}{*}{0.126} & 66.9 & 33.8 & 27.2 & \multirow[t]{2}{*}{0.278} \\
\hline Female & 21 & 52.4 & 28.6 & 23.8 & & 61.9 & 47.6 & 38.1 & \\
\hline \multicolumn{10}{|l|}{ Age (years) } \\
\hline$<46.9$ & 79 & 39.2 & 24.1 & 21.5 & \multirow[t]{2}{*}{0.754} & 64.6 & 35.4 & 27.8 & \multirow[t]{2}{*}{0.801} \\
\hline$\geq 46.9$ & 78 & 37.2 & 24.4 & 17.9 & & 57.0 & 35.9 & 29.5 & \\
\hline \multicolumn{10}{|l|}{ Ascites } \\
\hline No & 125 & 39.2 & 23.2 & 19.2 & \multirow[t]{2}{*}{0.946} & 64.0 & 34.4 & 27.2 & \multirow[t]{2}{*}{0.973} \\
\hline Yes & 32 & 34.4 & 28.1 & 21.9 & & 50.0 & 40.6 & 34.4 & \\
\hline \multicolumn{10}{|l|}{ Cirrhosis } \\
\hline No & 24 & 29.2 & 20.8 & 16.7 & \multirow[t]{2}{*}{0.498} & 54.2 & 33.3 & 25.0 & \multirow[t]{2}{*}{0.580} \\
\hline Yes & 133 & 39.8 & 24.8 & 20.3 & & 66.7 & 36.1 & 29.3 & \\
\hline \multicolumn{10}{|l|}{ ALT (U/l) } \\
\hline$<50.4$ & 99 & 42.4 & 26.3 & 20.2 & \multirow[t]{2}{*}{0.282} & 60.6 & 36.4 & 30.3 & \multirow[t]{2}{*}{0.491} \\
\hline$\geq 50.4$ & 58 & 31.0 & 20.7 & 19.0 & & 62.1 & 34.5 & 25.9 & \\
\hline \multicolumn{10}{|l|}{$\mathrm{TB}(\mu \mathrm{mol} / \mathrm{l})$} \\
\hline$<16.9$ & 87 & 40.2 & 24.1 & 19.5 & \multirow[t]{2}{*}{0.464} & 67.8 & 39.1 & 28.7 & \multirow[t]{2}{*}{0.361} \\
\hline$\geq 16.9$ & 70 & 35.7 & 24.3 & 20.0 & & 52.9 & 31.4 & 28.6 & \\
\hline \multicolumn{10}{|l|}{ HBsAg } \\
\hline Negative & 11 & 45.5 & 27.3 & 18.2 & 0.844 & 45.5 & 36.4 & 18.2 & 0.545 \\
\hline Positive & 146 & 37.7 & 24.0 & 19.9 & & 62.3 & 35.6 & 29.5 & \\
\hline HCVAb & & & & & & & & & \\
\hline Negative & 155 & 37.4 & 23.2 & 19.4 & 0.316 & 60.6 & 34.8 & 28.4 & 0.360 \\
\hline Positive & 2 & 100 & 100 & 50 & & 100 & 100 & 50 & \\
\hline $\operatorname{ALB}(g / l)$ & & & & & & & & & \\
\hline$<41.7$ & 74 & 37.8 & 27.0 & 23.0 & 0.752 & 56.8 & 37.8 & 32.4 & 0.750 \\
\hline$\geq 41.7$ & 83 & 38.6 & 21.7 & 16.9 & & 65.1 & 33.3 & 25.0 & \\
\hline Tumor location & & & & & & & & & \\
\hline Left lobe & 49 & 36.7 & 26.5 & 20.7 & 0.822 & 63.3 & 38.8 & 34.7 & 0.697 \\
\hline Right lobe & 89 & 38.2 & 22.5 & 20.2 & & 61.8 & 33.7 & 27.0 & \\
\hline Left and right lobes & 19 & 42.1 & 26.3 & 21.1 & & 52.6 & 36.8 & 21.1 & \\
\hline Edmonson grade & & & & & & & & & \\
\hline I + II & 80 & 41.3 & 27.5 & 26.3 & 0.284 & 68.8 & 41.3 & 30.0 & 0.260 \\
\hline $\mathrm{III}+\mathrm{IV}$ & 77 & 35.1 & 20.8 & 19.5 & & 53.2 & 29.9 & 27.3 & \\
\hline Adjuvant TACE & & & & & & & & & \\
\hline No & 126 & 42.1 & 27.0 & 21.4 & 0.161 & 61.9 & 38.1 & 29.4 & 0.635 \\
\hline Yes & 31 & 22.6 & 12.9 & 12.9 & & 58.1 & 25.8 & 25.8 & \\
\hline
\end{tabular}


Table III continued. Survival analysis of the patients in the experimental group.

\begin{tabular}{|c|c|c|c|c|c|c|c|c|c|}
\hline \multirow[b]{2}{*}{ Variables } & \multirow{2}{*}{$\begin{array}{l}\text { No. of } \\
\text { patients }\end{array}$} & \multicolumn{3}{|c|}{ DFS rate $(\%)$} & \multirow[b]{2}{*}{ P-value } & \multicolumn{3}{|c|}{ OS rate $(\%)$} & \multirow[b]{2}{*}{ P-value } \\
\hline & & 1-year & 3-years & 5-years & & 1-year & 3-years & 5-years & \\
\hline \multicolumn{10}{|c|}{ Resection margin $(\mathrm{cm})$} \\
\hline$\leq 0.5$ & 28 & 35.7 & 25.0 & 14.3 & \multirow[t]{3}{*}{0.123} & 60.7 & 32.1 & 25.0 & \multirow[t]{3}{*}{0.182} \\
\hline $0.5-1.0$ & 52 & 28.8 & 17.3 & 13.5 & & 57.7 & 34.6 & 19.2 & \\
\hline$\geq 1.0$ & 77 & 45.5 & 28.6 & 24.7 & & 63.6 & 37.7 & 36.4 & \\
\hline \multicolumn{10}{|l|}{$\mathrm{AFP}(\mathrm{ng} / \mathrm{ml})$} \\
\hline$<400$ & 64 & 48.4 & 28.1 & 20.3 & \multirow[t]{2}{*}{0.034} & 75.0 & 46.9 & 35.9 & \multirow[t]{2}{*}{0.014} \\
\hline$\geq 400$ & 93 & 31.2 & 21.5 & 19.4 & & 51.6 & 28.0 & 23.7 & \\
\hline \multicolumn{10}{|l|}{ Tumor number } \\
\hline Single & 104 & 45.2 & 27.9 & 23.1 & \multirow[t]{2}{*}{0.001} & 68.3 & 39.4 & 32.7 & \multirow[t]{2}{*}{0.010} \\
\hline Multiple & 53 & 24.5 & 17.0 & 11.3 & & 47.2 & 28.3 & 20.8 & \\
\hline \multicolumn{10}{|c|}{ Tumor size (cm) } \\
\hline$<9.1$ & 94 & 45.7 & 26.6 & 20.2 & \multirow[t]{2}{*}{0.026} & 68.1 & 43.6 & 33.0 & \multirow[t]{2}{*}{0.037} \\
\hline$\geq 9.1$ & 63 & 27.0 & 20.6 & 19.0 & & 47.6 & 23.8 & 22.2 & \\
\hline \multicolumn{10}{|l|}{ Tumor rupture } \\
\hline No & 120 & 44.2 & 28.3 & 22.5 & \multirow[t]{2}{*}{0.001} & 67.5 & 42.5 & 34.2 & \multirow[t]{2}{*}{$<0.001$} \\
\hline Yes & 37 & 18.9 & 10.8 & 10.8 & & 40.5 & 13.5 & 10.8 & \\
\hline \multicolumn{10}{|c|}{ Vascular invasion } \\
\hline Microscopic & 91 & 50.5 & 36.3 & 28.6 & \multirow[t]{2}{*}{$<0.001$} & 72.5 & 47.0 & 38.5 & \multirow[t]{2}{*}{$<0.001$} \\
\hline Macroscopic & 66 & 19.7 & 6.1 & 6.1 & & 43.9 & 18.2 & 15.2 & \\
\hline
\end{tabular}

DFS, disease-free survival; OS, overall survival; ALT, alanine aminotransferase; TB, total bilirubin; HBsAg, hepatitis B surface antigen; HCVAb, hepatitis C virus antibody; ALB, albumin; TACE, transarterial chemoembolization; AFP, $\alpha$-fetoprotein.

Table IV. Multivariate analysis of DFS for the experimental group.

\begin{tabular}{lcccc}
\hline Variables & B & SE & Hazard ratio & P-value \\
\hline AFP & 0.249 & 0.206 & 1.283 & 0.227 \\
Tumor number & 0.336 & 0.102 & 1.399 & 0.001 \\
Tumor size & 0.133 & 0.211 & 1.143 & 0.527 \\
Tumor rupture & 0.489 & 0.221 & 1.631 & 0.027 \\
Macrovascular invasion & 0.261 & 0.119 & 1.299 & 0.027 \\
\hline
\end{tabular}

DFS, disease-free survival; B, regression coefficient; SE, standard error; AFP, $\alpha$-fetoprotein.

In clinical practice, certain patients presenting with vascular invasion may achieve satisfactory survival following surgical comprehensive treatment (5). The purpose of the present study was to investigate the prognosis factors of patients with HCC and vascular invasion, in order to establish a classification criteria based on these factors that would aid the identification of patients suitable for surgical treatment.

In the present study, the number of tumors was demonstrated to be an independent risk factor of recurrence and survival. Due to its invasive nature, $\mathrm{HCC}$ tends to form multiple nodules that lead to postoperative recurrence (14). Zhong et al (15) suggested that in patients with HCC and preserved liver function, the presence of multinodular tumors was not a contraindication for hepatic resection. However, previous studies have suggested that patients with multiple tumors have a higher probability of worse survival prognosis than those with a single tumor, due to the significant risk of recurrence following hepatic resection for HCC (16). This hypothesis is supported by the results of the studies by Wang et al (17), who observed that the prognosis of patients with multinodular HCC was poor, compared to those with single-nodular HCC.

The present study revealed that the incidence of spontaneous tumor rupture in patients with $\mathrm{HCC}$ affected by PVTT was higher than in patients with HCC overall (22.6 vs. $12.1 \%$, respectively). Tumor spontaneous rupture was observed to be an independent risk factor of recurrence and survival for patients with HCC 
Table V. Multivariate analysis of OS for the experimental group.

\begin{tabular}{lcccc}
\hline Variables & B & SE & Hazard ratio & P-value \\
\hline AFP & 0.385 & 0.207 & 1.470 & 0.063 \\
Tumor number & 0.236 & 0.1045 & 1.266 & 0.024 \\
Tumor size & 0.033 & 0.2105 & 1.034 & 0.877 \\
Tumor rupture & 0.646 & 0.224 & 1.907 & 0.004 \\
Macrovascular invasion & 0.246 & 0.120 & 1.279 & 0.040 \\
\hline
\end{tabular}

OS, overall survival; B, regression coefficient; SE, standard error; AFP, $\alpha$-fetoprotein.

Table VI. Survival analysis of patients in the low, medium and high-risk groups within the experimental group.

\begin{tabular}{|c|c|c|c|c|c|c|c|c|c|}
\hline \multirow[b]{2}{*}{ Groups } & \multirow{2}{*}{$\begin{array}{c}\text { No. of } \\
\text { patients }\end{array}$} & \multicolumn{3}{|c|}{ DFS rate $(\%)$} & \multirow[b]{2}{*}{ P-value } & \multicolumn{3}{|c|}{ OS rate $(\%)$} & \multirow[b]{2}{*}{ P-value } \\
\hline & & 1-year & 3-years & 5-years & & 1-year & 3-years & 5-years & \\
\hline 1 & 52 & 61.5 & 44.2 & 34.6 & $<0.001$ & 86.5 & 57.7 & 50.0 & $<0.001$ \\
\hline 2 & 58 & 34.5 & 20.7 & 17.2 & & 55.2 & 31.0 & 22.4 & \\
\hline 3 & 47 & 14.9 & 6.4 & 6.4 & & 40.4 & 17.0 & 12.8 & \\
\hline
\end{tabular}

DFS, disease-free survival; OS, overall survival.

Table VII. Survival analysis of patients in the low-, medium- and high-risk groups within the validation group.

\begin{tabular}{|c|c|c|c|c|c|c|c|c|c|}
\hline \multirow[b]{2}{*}{ Groups } & \multirow{2}{*}{$\begin{array}{c}\text { No. of } \\
\text { patients }\end{array}$} & \multicolumn{3}{|c|}{ DFS rate $(\%)$} & \multirow[b]{2}{*}{ P-value } & \multicolumn{3}{|c|}{ OS rate $(\%)$} & \multirow[b]{2}{*}{$\mathrm{P}$-value } \\
\hline & & 1-year & 3 -years & 5-years & & 1-year & 3-years & 5-years & \\
\hline 1 & 33 & 60.6 & 48.5 & 42.4 & $<0.001$ & 72.7 & 60.6 & 51.5 & $<0.001$ \\
\hline 2 & 27 & 34.8 & 3.7 & 3.7 & & 63.0 & 18.5 & 7.4 & \\
\hline 3 & 17 & 5.9 & 0.0 & 0.0 & & 17.6 & 0.0 & 0.0 & \\
\hline
\end{tabular}

DFS, disease-free survival; OS, overall survival.

affected by PVTT, and patients with tumor rupture exhibited a higher probability of poor prognosis than those without tumor rupture. The mechanism of spontaneous tumor rupture in HCC has been proposed to be associated with rapid tumor growth that may lead to tumor necrosis; tumor invasion of the venous, resulting in venous occlusion; or increased macrophages and neutrophils-mediated vascular endothelial cell permeability, which may damage the walls of the blood vessels (18).

Previous studies have confirmed that macrovascular invasion was associated with the malignant degree of HCC, and that the degree of vascular invasion affected the prognosis of patients with HCC (19). These studies also suggested that DFS and $\mathrm{OS}$ rates in patients with $\mathrm{HCC}$ presenting macrovascular invasion were lower than those in patients without macrovascular invasion (20).

Previous studies have suggested that the levels of AFP were associated with survival following resection $(21,22)$. By contrast, the levels of AFP were not observed to be a prognostic predictor for survival in other studies (23). In the present study, the levels of AFP were not able to predict the survival of patients with HCC and PVTT, following hepatic resection. The fact that the levels of AFP were observed to be important prognostic factors for survival but did not directly correlate with tumor size or number, suggests that AFP may display other properties within the complex biology of HCC (20).

Previous studies indicated that the extent of liver resection margin was an independent prognostic factor for OS $(24,25)$. However, the present study demonstrated that the extent of liver resection margin did not influence the postoperative OS, in agreement with previous reports $(26,27)$. This apparent discrepancy may be explained by the fact that HCC has a propensity to disseminate via vascular invasion. Thus, intrahepatic metastasis is likely to be present beyond $1 \mathrm{~cm}$ in the majority of patients prior to operation. The results derived from the present study suggest that a resection margin $\geq 1 \mathrm{~cm}$ had little beneficial effect on prolonging the OS rate for patients with HCC and PVTT who underwent hepatic resection.

Cheng et al (28) proposed that the type of tumor thrombi may aid to determine the treatment plan and assess the prognosis of patients with HCC presenting PVTT. In their 


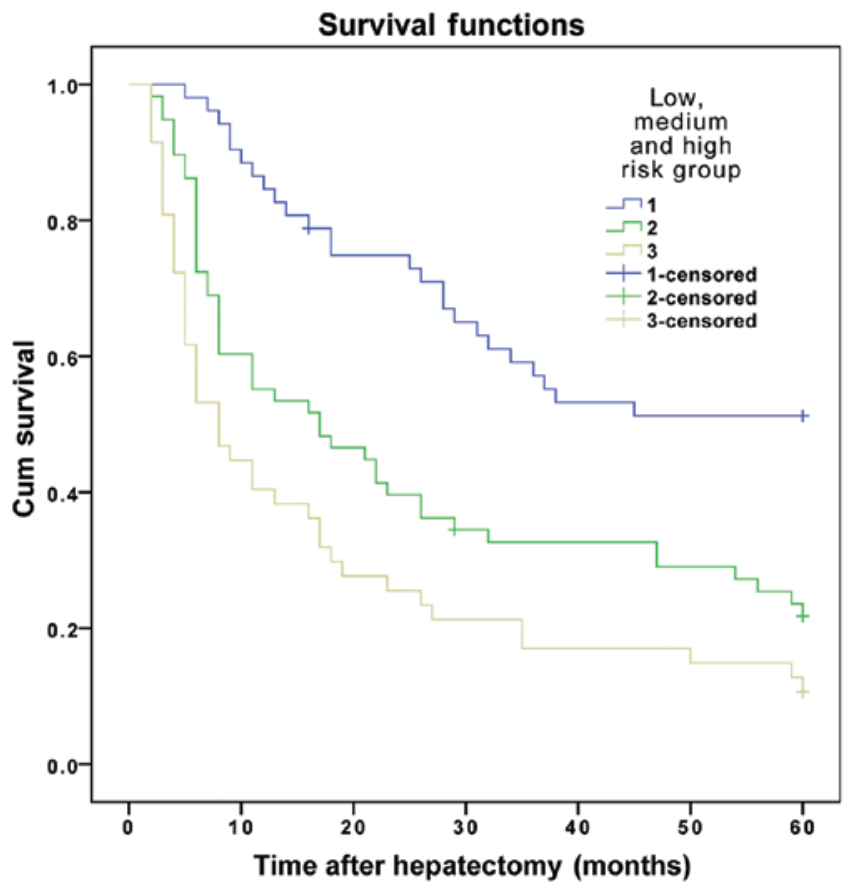

Figure 2. Overall survival curve for patients in the experimental group, who were divided into low-, medium- and high-risk groups. Cum, cumulative.

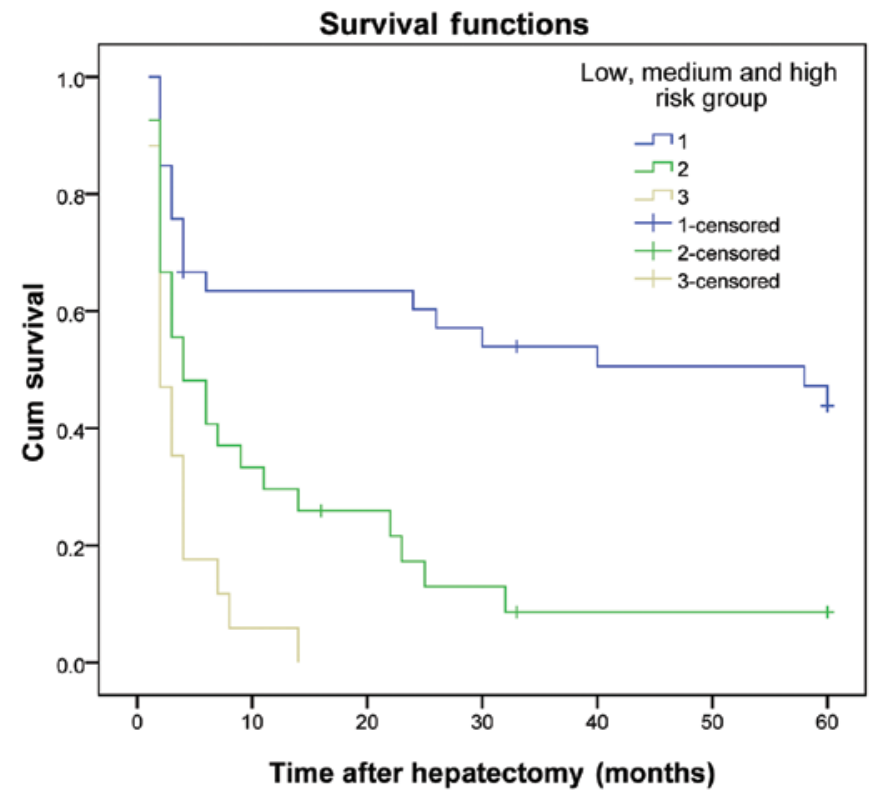

Figure 3. Disease-free survival curve for patients in the validation group, who were divided into low-, medium- and high-risk groups. Cum, cumulative.

studies, the authors observed that there was no significant difference between the DFS and OS rates of patients with HCC affected by primary branch of PVTT, compared to those exhibiting secondary branch of PVTT. However, the results from the present study differ from other reports in the literature (29), possibly due to the relatively small size of the sample. Thus, further studies are required to confirm these preliminary observations.

Chung et al (30) compared the outcomes of patients treated with transarterial chemoembolization (TACE) with those of patients receiving supportive care according to their

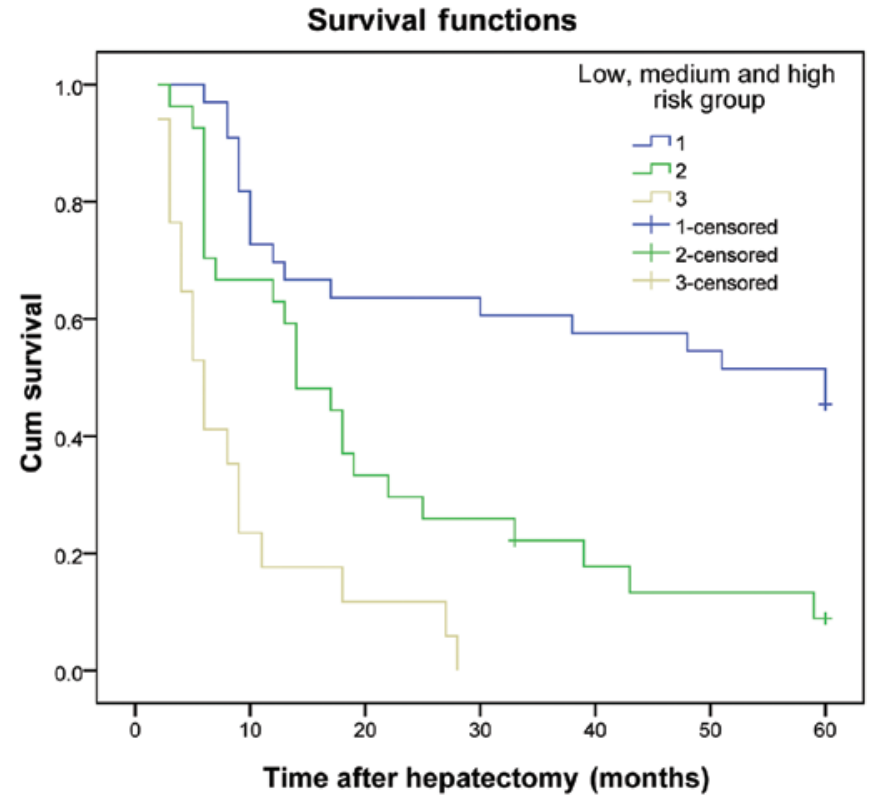

Figure 4. Overall survival curve for patients in the validation group, who were divided into low-, medium- and high-risk groups. Cum, cumulative.

Child-Pugh class. The authors demonstrated that TACE may be performed safely and improve the OS of patients with HCC. However, the resuls from the present study indicate that TACE was not capable of benefiting patients with HCC and PVTT, in regards to their DFS and OS rates. This may be associated with the small number of cases used in the study, and the fact that the majority of patients were not treated with TACE, but only those in poor condition.

Several staging methods or liver staging systems for HCC have been proposed, including those described by Okuda, Cancer of the Liver Italian Program, Barcelona Clinic Liver Cancer, Model for End-Stage Liver Disease, Chinese University Prognostic Index, Japanese Integrated System, Tumor Node Metastasis, Groupe d'Etude de Traitement du Carcinoma Hepatocellulaire and Liver Cancer Study Group of Japan (31). However, the predictive performance of the existing prognostic systems is non-ideal, due to their inherent limitations, the non-universal reproducibility and transportability of the results in different populations and other key factors that must be also considered (31). Previous studies $(32,33)$ have reported that vascular invasion is a useful parameter in the grading and staging system of patients with HCC. However, this was not observed in the present study.

In the present study, patients with HCC presenting PVTT were divided into low-, medium- or high-risk groups, according to the number of risk factors exhibited by the patients. The DFS and OS rates for these groups were observed to be significantly different. These results suggest that an increase in the number of risk factors leads to worse DFS and OS rates. Thus, the prognostic model proposed in the present study, based on the above risk factors, may be used to guide the treatment, predict the prognosis, enhance the therapeutic efficiency and improve the survival rates of patients with HCC affected by PVTT.

In conclusion, the results of the present study have demonstrated that parameters such as the number of tumors, tumor 
rupture and macrovascular invasion may affect the postoperative outcomes of patients with HCC and PVTT following hepatectomy. In addition, the prognostic model established, based on the number of risk factors exhibited by the patient, may be used to guide the treatment and predict the prognosis of these patients.

\section{Acknowledgements}

This study was supported by grants from the National Natural Science Foundation of China (grant no. 81172037/ H1606), Guangzhou Municipal Science and Technology Project of China (grant no. 2012J4100078), and Guangdong Province Science and Technology Project of China (grant no. 2013B021800159).

\section{References}

1. El-Serag HB and Rudolph KL: Hepatocellular carcinoma: Epidemiology and molecular carcinogenesis. Gastroenterology 132: 2557-2576, 2007.

2. Faber W, Sharafi S, Stockmann M, Denecke T, Sinn B, Puhl G, Bahra M, Malinowski MB, Neuhaus P and Seehofer D: Long-term results of liver resection for hepatocellular carcinoma in noncirrhotic liver. Surgery 153: 510-517, 2013

3. Ikai I, Arii S, Kojiro M, Ichida T, Makuuchi M, Matsuyama Y, Nakanuma Y, Okita K, Omata M, Takayasu K and Yamaoka Y: Reevaluation of prognostic factors for survival after liver resection in patients with hepatocellular carcinoma in a Japanese nationwide survey. Cancer 101: 796-802, 2004.

4. Guglielmi A, Ruzzenente A, Conci S, Valdegamberi A, Vitali M, Bertuzzo F, De Angelis M, Mantovani G and Iacono C: Hepatocellular carcinoma: Surgical perspectives beyond the barcelona clinic liver cancer recommendations. World J Gastroenterol 20: 7525-7533, 2014.

5. Peng ZW, Guo RP, Zhang YJ, Lin XJ, Chen MS and Lau WY: Hepatic resection versus transcatheter arterial chemoembolization for the treatment of hepatocellular carcinoma with portal vein tumor thrombus. Cancer 118: 4725-4736, 2012

6. Zhang T, Huang JW, Bai YN, Wu H and Zeng Y: Recurrence and survivals following hepatic resection for hepatocellular carcinoma with major portal/hepatic vein tumor thrombus. Hepatol Res 44: 761-768, 2014.

7. Edmondson HA and Steiner PE: Primary carcinoma of the liver: A study of 100 cases among 48,900 necropsies. Cancer 7: 462-503, 1954

8. Vauthey JN, Dixon E, Abdalla EK, et al: Pretreatment assessment of hepatocellular carcinoma: Expert consensus statement. HPB (Oxford) 12: 289-299, 2010

9. Buck AK, Herrmann K, Eckel F, and Beer AJ: Pancreatic and hepatobiliary cancers. Methods Mol Biol 727: 243-264, 2011.

10. Regimbeau JM, Abdalla EK, Vauthey JN, Lauwers GY, Durand F, Nagorney DM, Ikai I, Yamaoka Y and Belghiti J: Risk factors for early death due to recurrence after liver resection for hepatocellular carcinoma: results of a multicenter study. J Surg Oncol 85: 36-41, 2004.

11. Masuda T, Beppu T, Ishiko T, et al: Intrahepatic dissemination of hepatocellular carcinoma after local ablation therapy. J Hepatobiliary Pancreat Surg 15: 589-595, 2008.

12. Yan T, Zhao JJ, Bi XY, et al: Prognosis of hepatocellular carcinoma: A study of 832 cases. Zhonghua Zhong Liu Za Zhi 35: 54-58, 2013.(In Chinese).

13. Duseja A: Staging of hepatocellular carcinoma. J Clin Exp Hepatol 4: S74-S79, 2014

14. Poon RT, Fan ST, Lo CM, Liu CL and Wong J: Difference in tumor invasiveness in cirrhotic patients with hepatocellular carcinoma fulfilling the Milan criteria treated by resection and transplantation: Impact on long-term survival. Ann Surg 245: 51-58, 2007.

15. Zhong JH, Ke Y, Gong WF, Xiang BD, Ma L, Ye XP, Peng T, Xie GS and Li LQ: Hepatic resection associated with good survival for selected patients with intermediate and advanced-stage hepatocellular carcinoma. Ann Surg 260: 329-340, 2014.
16. Ishizawa T, Hasegawa K, Aoki T, Takahashi M, Inoue Y, Sano K, Imamura H, Sugawara Y, Kokudo N and Makuuchi M: Neither multiple tumors nor portal hypertension are surgical contraindications for hepatocellular carcinoma. Gastroenterology 134: 1908-1916, 2008

17. Wang BW, Mok KT, Liu SI, Chou NH, Tsai CC, Chen IS, Yeh MH and Chen YC: Is hepatectomy beneficial in the treatment of multinodular hepatocellular carcinoma? J Formos Med Assoc 107: 616-626, 2008.

18. Lai ECH and Lau WY: Spontaneous rupture of hepatocellular carcinoma: A systematic review. Arch Surg 141: 191-198, 2006.

19. Matono R, Yoshiya S, Motomura T, Toshima T, Kayashima H, Masuda T, Yoshizumi T, Taketomi A, Shirabe K and Maehara Y: Factors linked to longterm survival of patients with hepatocellular carcinoma accompanied by tumour thrombus in the major portal vein after surgical resection. HPB (Oxford) 14: 247-253, 2012.

20. Sorrentino P, Tarantino L, D’Angelo S, Terracciano L, Ferbo U, Bracigliano A, Panico L, De Chiara G, Lepore M, De Stefano N et al: Validation of an extension of the international non-invasive criteria for the diagnosis of hepatocellular carcinoma to the characterization of macroscopic portal vein thrombosis. J Gastroenterol Hepatol 26: 669-677, 2011.

21. Zhou L, Rui JA, Wang SB, Chen SG and Qu Q: Prognostic factors of solitary large hepatocellular carcinoma: The importance of differentiation grade. Eur J Surg Oncol 37: 521-525, 2011.

22. Santambrogio R, Opocher E, Costa M, Barabino M, Zuin M, Bertolini E, De Filippi F and Bruno S: Hepatic resection for 'BCLC stage A' hepatocellular carcinoma. The prognostic role of $\alpha$-fetoprotein. Ann Surg Oncol 19: 426-434, 2012.

23. Kim HS, Park JW, Jang JS, Kim HJ, Shin WG, Kim KH, Lee JH, Kim HY and Jang MK: Prognostic values of alpha-fetoprotein and protein induced by vitamin $\mathrm{K}$ absence or antagonist-II in hepatitis B virus-related hepatocellular carcinoma: A prospective study. J Clin Gastroenterol 43: 482-488, 2009.

24. Shi M, Guo RP, Lin XJ, Zhang YQ, Chen MS, Zhang CQ, Lau WY and Li JQ: Partial hepatectomy with wide versus narrow resection margin for solitary hepatocellular carcinoma: A prospective randomized trial. Ann Surg 245: 36-43, 2007.

25. Wang J, Xu LB, Liu C, Pang HW, Chen YJ and Ou QJ: Prognostic factors and outcome of 438 Chinese patients with hepatocellular carcinoma underwent partial hepatectomy in a single center. World J Surg 34: 2434-2441, 2010.

26. Liu L, Miao R, Yang H, Lu X, Zhao Y, Mao Y, Zhong S, Huang J, Sang $\mathrm{X}$ and Zhao H: Prognostic factors after liver resection for hepatocellular carcinoma: A single-center experience from China. Am J Surg 203: 741-750, 2012.

27. Giuliante F, Ardito F, Pinna AD, Sarno G, Giulini SM, Ercolani G, Portolani N, Torzilli G, Donadon M, Aldrighetti L, et al: Liver resection for hepatocellular carcinoma $\leq 3 \mathrm{~cm}$ : Results of an Italian multicenter study on 588 patients. J Am Coll Surg 215: 244-254, 2012

28. Cheng SQ, Wu MC, Chen H, Shen F, Yang JH, Cong WM, Wang PJ and Zhao YX: Significance of typing of tumor thrombi in determination of treatment and assessment of prognosis of hepatocellular carcinoma with tumor thrombi in the portal vein. Zhonghua Yi Xue Za Zhi 84: 3-5, 2004. (In Chinese).

29. Shi J, Lai EC, Li N, Guo WX, Xue J, Lau WY, Wu MC and Cheng SQ: A new classification for hepatocellular carcinoma with portal vein tumor thrombus. J Hepatobiliary Pancreat Sci 18: 74-80, 2011.

30. Chung GE, Lee JH, Kim HY, Hwang SY, Kim JS, Chung JW, Yoon JH, Lee HS and Kim YJ: Transarterial chemoembolization can be safely performed in patients with hepatocellular carcinoma invading the main portal vein and may improve the overall survival. Radiology 258: 627-634, 2011

31. Maida M, Orlando E, Cammà C and Cabibbo G: Staging systems of hepatocellular carcinoma: A review of literature. World J Gastroenterol 20: 4141-4150, 2014.

32. Kinoshita A, Onoda H, Imai N, Iwaku A, Oishi M, Tanaka K, Fushiya N, Koike K, Nishino H, Matsushima M et al: The Glasgow Prognostic Score, an inflammation based prognostic score, predicts survival in patients with hepatocellular carcinoma. BMC Cancer 13: 52, 2013.

33. Liu C, Xiao GQ, Yan LN, Li B, Jiang L, Wen TF, Wang WT, $\mathrm{Xu}$ MQ and Yang JY: Value of $\alpha$-fetoprotein in association with clinicopathological features of hepatocellular carcinoma. World J Gastroenterol 19: 1811-1819, 2013. 